\title{
Effect of daily social media exposure on anxiety and depression disorders among cargo seafarers: a cross-sectional study
}

\author{
Arianne A. Zamora ${ }^{1} \oplus$, Zypher Jude G. Regencia ${ }^{2} \oplus$, Marilyn E. Crisostomo ${ }^{3}$, \\ Guido Van Hal ${ }^{1}\left(\mathbb{D}\right.$, Emmanuel S. Baja $^{2,4}{ }^{(1)}$
}

${ }^{1}$ Research Group Epidemiology and Social Medicine, Research Unit Medical Sociology and Health Policy, University of Antwerp, Antwerpen, Belgium

${ }^{2}$ Exposure Assessment, Epidemiology, and Risk Lab, Institute of Clinical Epidemiology, National Institutes of Health, University of the Philippines-Manila, Manila, Philippines

${ }^{3}$ Department of Behavioural Sciences, College of Arts and Sciences, University of the Philippines-Manila, Manila, Philippines ${ }^{4}$ Department of Clinical Epidemiology, College of Medicine, University of the Philippines-Manila, Manila, Philippines

\begin{abstract}
Background: Several studies have linked social media use to increased risks for anxiety and depression. Cargo seafaring is one occupation prone to constant mental health instability due to workload, social isolation, and harsh working conditions. We examined the effect of daily social media exposure, occupational experience, and socioeconomic factors on anxiety and depression disorders among cargo seafarers.

Materials and methods: We assessed the anxiety and depression disorders of 153 cargo seafarers using Generalised Anxiety Disorder-7 and Patient Health Questionnaire-9 scales. We fitted generalised linear models to estimate associations between depression and anxiety disorders and daily social media exposure, occupational experience, and socioeconomic factors.

Results: Approximately $30 \%$ and $37 \%$ of the seafarers had mild, moderate, or severe anxiety and depression disorders. The prevalence of anxiety was 2.68 times higher (adjusted prevalence ratio [aPR] 2.68, 95\% confidence interval [95\% Cl] 1.30-5.50) and 2.27 times higher (aPR 2.27; 95\% Cl 1.12-4.62) among seafarers who spend $>2$ to 4 hours and $>4$ hours each day, respectively, on social media compared to seafarers who spend only up to 2 hours. In addition, seafarers who were on social media daily for $>2$ to 4 hours (aPR 1.49; 95\% $\mathrm{Cl} 0.86-2.60$ ) and $>4$ hours (aPR 1.34; 95\% $\mathrm{Cl} 0.75-2.40$ ) had a higher prevalence of depression compared to seafarers who were on social media daily for only up to 2 hours. Non-Catholics or seafarers with $\leq 10$ years of occupational experience had a higher prevalence for anxiety and depression disorders than Catholics or seafarers with $>10$ years of occupational experience.

Conclusions: Daily social media exposure for $>2$ hours, working for $\leq 10$ years, or being a non-Catholic may contribute to the increase in the seafarers' susceptibility to depression and anxiety disorders. The establishment of support groups for cargo seafarers is warranted to promote mental health awareness and well-being.
\end{abstract}

(Int Marit Health 2021; 72, 1: 55-63)

Key words: anxiety disorder, Catholic, depression disorder, Generalised Anxiety Disorder-7, occupational experience, Patient Health Questionnaire-9, seafarers, social media 


\section{INTRODUCTION}

Social media has been integrated into the daily lives of many of its users. In 2016 , roughly 2.31 billion users globally used one or another form of social media [1]. As the number of users increases, social media has extended its reach into many facets of our everyday lives, from work to politics to communicating with friends and strangers and how we get and share information [2]. This widespread use of social media has led to many research studies examining social media's utilisation and its effects on our health and life. Various studies have been reported to assess its association with psychosocial health and overall well-being; however, results have been conflicting. In one review, internet usage may help increase self-esteem, perceived social support, and increased social capital while contributing to increased exposure to harm, social isolation, cyberbullying, and depression [3]. In another review, the effect of social media use on depression and anxiety is similarly inconclusive [4].

Depression and anxiety are the two most common mental health disorders worldwide. Depression affected approximately $4.4 \%$, or 322 million, of the world's population in 2015. Moreover, depression is also considered the single largest contributor to non-fatal health loss accounting for $7.5 \%$ (50 million) of all years lived with disability globally. In addition, 3.6\% of the population are diagnosed with an anxiety disorder [5]. Anxiety and depression are the most common mental health disorders among adolescents [6]. The prevalence of anxiety and depression has increased by $70 \%$ in the past 25 years [7]. Furthermore, these two disorders are comorbid conditions [8] while also with other morbidities. Depression and anxiety have adverse consequences, including impaired social relationships and increased risk of substance abuse, mental health problems, and suicide, one of the top 20 leading causes of death in the United States [9-11]. Aside from the direct costs from these illnesses to the individuals, costs from comorbid conditions account for a larger part of its economic burden [12]. These two conditions have also negatively impacted work performance and decreased economic productivity in the workforce $[13,14]$.

Many factors contribute to the development of depression and anxiety, such as genetics and environmental factors $[15,16]$. Due to the harsh environmental conditions in seafaring, mental health issues among crew members are not surprising. Seafaring is considered one of the most hazardous jobs globally [17]. Besides being exposed to occupational health hazards, seafarers are also prone to experiencing social isolation, given their extended deployment at sea and away from home $[18,19]$. In addition, the exact prevalence of anxiety, and depression, is not entirely known among the maritime population, with some studies offering inconsistent conclusions.
Furthermore, evidence from previous studies supports generally stable mental health among seafarers, including a low rate of medical repatriation due to psychological reasons and a decline in suicide rates in recent decades $[20,21]$. However, these findings do not guarantee a good mental health status among seafarers. Some studies report suicidal ideation among seafarers reported by their colleagues and increased prevalence of stress and fatigue [18]. With the advent of the internet and social media comes a more accessible avenue for communication. Social media encompasses web-based and mobile-based applications that allow users to exchange generated content and build virtual networks that are ubiquitously available. Aside from social networking sites such as Twitter and Facebook, it also includes really simple syndication feeds, news, blogs, and all unstructured text available on the internet [22]. Understanding how the use and access to social media affect their mental health will help inform policies that may influence their lives at sea. Moreover, the literature also indicated an increased use of social media due to the increased symptoms of depression and anxiety. The relationship between social media use and symptoms of depression and anxiety is complex due to the bidirectional effects [23].

The impact of social media exposure and mental illness on workers' occupational health cannot be overstated. Several factors have been linked to increased adverse mental health effects due to social media exposure. In addition, various mechanisms could account for the association between social media use and mental health disorder. People who engage in high levels of social media use may experience more inadequate quality sleep, which may be a mediator on the pathway to depression or anxiety [24]. Time spent on social media may also increase the risk of experiencing cyberbullying, which may lead to an increased risk for depression, particularly in teenagers and young adults [25]. Aside from age and time spent on social media, another factor that may affect the mental illness includes religious beliefs or spirituality. A study suggested that religious beliefs and practices were consistently associated with greater life satisfaction and psychological well-being. This association led to less anxiety and fear, increased hope and optimism, and decreased depression [26].

In this study, we focused on estimating the prevalence of depression and anxiety among cargo merchant seafarers and examining the effects of daily social media exposure, occupational experience, and socioeconomic factors on anxiety and depression.

\section{MATERIALS AND METHODS STUDY POPULATION}

This cross-sectional study involved 153 international seafarers who were enrolled from March 2019 to June 2019. Participants' recruitment was face-to-face at the 
Antwerp Seafarer Centre in Antwerp, Belgium, and through some online social media platforms. Seafarers with electronic devices who agreed to participate in the study were given a link to access the web-based self-administered questionnaire in English. Eligible study participants were 18-65 years old, male, currently deployed on a merchant cargo ship, and worked on board for at least 2 months. Excluded from the study were female seafarers, given the expectedly low number of respondents. In addition, the web-based questionnaire included the demographic profile of the seafarer, their employment history, nationality, religion, daily social media use, and screening tools for the assessment of anxiety and depression disorders. Prior to answering the questionnaire, each participant was asked to consent before proceeding with the survey questionnaire. This study obtained institutional ethics approval from an independent research ethics committee.

\section{EXPOSURE ASSESSMENT OF DAILY SOCIAL MEDIA USAGE}

Daily social media use was assessed by adding the participants' self-reported hours on social media during and after their work shift. The total was used to group the daily social media exposure of seafarers into three categories: 0 to 2 hours, $>2$ hours to 4 hours, and more than 4 hours.

\section{HEALTH OUTCOME ASSESSIMENT OF ANXIETY AND DEPRESSION}

The severity of the seafarers' anxiety was assessed using the 7-item Generalised Anxiety Disorder-7 (GAD-7), a standard tool for anxiety disorder assessment. Respondents were asked, "Over the last two weeks, how often have you been bothered by the following problems?" The response anxiety scale options for the 7 -item questions were "not at all," "several days," "more than half the days," and "nearly every day," and each scale option was scored as $0,1,2$, and 3 , respectively. The seafarers were grouped into four outcome categories based on their total GAD-7 score using a diagnostic algorithm for anxiety disorders: 0 to 4-no/minimal anxiety; 5 to $9-$ mild anxiety; 10 to $14-$ moderate anxiety; and 15 to 21 - severe anxiety [27].

Patient Health Questionnaire-9 (PHQ-9), a 9-item tool representing the nine Diagnostic and Statistical Manual of Mental Disorders (DSM-IV) criteria of depressive disorder, was used to assess the severity of the seafarers' depression. Response depression scale options were identical to the GAD-7 questionnaire used for anxiety disorder assessment. Seafarers, based on their total PHQ-9 score, were grouped into no/minimal depression (0 to 4), mild (5 to 9 ), moderate (10 to 14 ), moderately severe ( 15 to 19 ), and severe (20 to 27) using a diagnostic algorithm for major depressive or other depressive disorders [28]. Both the PHQ-9 and GAD-7 as- sessment tools have strong internal validity, test-retest reliability, and construct and factor structure validity [29].

\section{STATISTICAL ANALYSIS}

We calculated the descriptive statistics for the demographic profile, daily social media use, and the anxiety and depression disorder health outcomes. The correlation coefficients were also calculated to evaluate the relationship between anxiety, depression, covariates, and daily social media use.

Associations between depression and anxiety disorders and daily social media use were estimated using generalised linear models with Poisson distribution and log link function and with a robust variance estimator, a more appropriate approach to analyse cross-sectional data with common health outcomes [30-33]. In addition, seafarers were classified into two groups according to their total PHQ-9 score (no/minimal depression: score $\leq 4$; with mild to severe depression: score > 4) and GAD-7 score (no/minimal anxiety: score $\leq 4$; with mild to severe anxiety: score $>4)$. Furthermore, generalised linear models were fitted to account for the heterogeneity in the seafarer's overall anxiety and depression disorders.

In all the models, we controlled for age (young adult; adult), relationship status (in a relationship; single/no relationship), educational attainment (college graduate; a college-level student or less), religion (Catholic; non-Catholic), nationality (Filipino; non-Filipino), years working as a seafarer ( $\leq 10$ years; $>10$ years), months on the current contract ( $\leq 6$ months; > 6 months), and employment status (officer; staff). The sociodemographic characteristics and occupational experience used were chosen a priori as potentially important predictors of anxiety and depression disorders [34, 35].

Effect size estimates were reported as adjusted prevalence ratio (aPR) with a 95\% confidence interval $(95 \% \mathrm{Cl})$ for the effect of daily social media use and other factors on depression and anxiety disorders. STATA 12 was used in the statistical analyses (www.stata.com/stata12/). P-values of $\leq 0.05$ were considered to be statistically significant.

\section{RESULTS}

One-hundred fifty-three (153) eligible participants were included in the study. Participants had a mean $( \pm$ standard deviation) age of $31.0 \pm 8.3$ years, with $87.6 \%$ being Filipinos. Most of them were Catholic (75.2\%), at least a college graduate (84.3\%), and with 10 years or less work experience (79.1\%), while only about $37.2 \%$ were in a relationship. Participants' self-reported hours on social media during and after their work shift, $1 / 3$ of them spent 0 to 2 hours on social media, approximately 3 out of 10 spent $>2$ to 4 hours, and about 3 out of 10 spent $>4$ hours, respectively. The survey on depression disorders revealed that most of them had no/minimal depression (62.7\%), while 
Table 1. Study characteristics of the seafarer participants $(n=153)$

\begin{tabular}{|c|c|c|}
\hline Characteristics & $\mathbf{N}$ & Values \\
\hline Age [years] & 152 & $31.0 \pm 8.3$ \\
\hline Young adult (21-25 years old) & 41 & 26.8 \\
\hline Adult $(>25$ years old) & 111 & 72.5 \\
\hline No data/missing & 1 & 0.7 \\
\hline In a relationship & 57 & 37.2 \\
\hline At least a college graduate & 129 & 84.3 \\
\hline Catholic & 115 & 75.2 \\
\hline Filipino & 134 & 87.6 \\
\hline$\leq 10$ years of work experience & 121 & 79.1 \\
\hline$>6$ months on the current contract & 59 & 38.6 \\
\hline Officer of the vessel & 54 & 35.3 \\
\hline \multicolumn{3}{|l|}{ Hours spent on social media: } \\
\hline 0 to 2 hours & 51 & 33.3 \\
\hline$>2$ to 4 hours & 47 & 30.7 \\
\hline$>4$ hours & 48 & 31.4 \\
\hline No data/missing & 7 & 4.6 \\
\hline \multicolumn{3}{|l|}{ PHQ-9 score distribution: } \\
\hline No/minimal & 96 & 62.7 \\
\hline Mild & 37 & 24.2 \\
\hline Moderate & 11 & 7.2 \\
\hline Moderate severe & 7 & 4.6 \\
\hline Severe & 2 & 1.3 \\
\hline \multicolumn{3}{|l|}{ GAD-7 score distribution: } \\
\hline No/Minimal & 107 & 69.9 \\
\hline Mild & 29 & 18.9 \\
\hline Moderate & 16 & 10.5 \\
\hline Severe & 1 & 0.7 \\
\hline
\end{tabular}

Data are shown as mean \pm standard deviation or per cent. GAD-7 - Generalised Anxiety Disorder-7; PHQ-9 - Patient Health Questionnaire-9

almost one-fourth of the participants had mild depression. In addition, the survey collected on anxiety disorders also showed that nearly 7 out of 10 had no/minimal anxiety, while almost one-fifth had mild anxiety. Furthermore, only about $1.3 \%$ and $0.7 \%$ had severe depression and anxiety, respectively. Table 1 summarises the study characteristics of the seafarers in detail.

\section{EFFECT OF DAILY SOCIAL MEDIA USE ON ANXIETY AND DEPRESSION DISORDERS}

Figure 1 shows the estimated effect of daily social media use for various hourly exposure on depression (Fig. 1A) and anxiety (Fig. 1B) disorders. The linear models showed that seafarers' exposure to daily social media use was associated with an increased prevalence for both anxiety and depression. The prevalence of anxiety was 2.68 times higher (aPR 2.68, 95\% Cl 1.30-5.50, p < 0.01) and 2.27 times higher (aPR 2.27, 95\% Cl 1.12-4.62, p = 0.02) among sea- farers who spend $>2$ to 4 hours daily and $>4$ hours daily, respectively, on social media compared to seafarers who spend only up to 2 hours daily on social media. Additionally, seafarers who were on social media daily for $>2$ to 4 hours and $>4$ hours had a higher prevalence of depression (aPR 1.49; 95\% Cl 0.86-2.60; $p=0.16$ and aPR 1.34, 95\% Cl $0.75-2.40 ; p=0.32$, respectively) compared to seafarers who were on social media daily for only up to 2 hours.

\section{EFFECT OF OCCUPATIONAL EXPERIENCE AND SOCIO-ECONOMIC FACTORS ON ANXIETY AND DEPRESSION DISORDERS}

Figure 2 shows the occupational experience and socio-economic factors associated with anxiety and depression disorders for the seafarer participants. Participants with $\leq 10$ years of work experience had approximately 3 times and 2 times higher prevalence of depression (aPR 3.11; 95\% $\mathrm{Cl} 1.16-8.36$ ) and anxiety (aPR 2.02; 95\% Cl 0.73-5.61), respectively, compared to participants with $>10$ years of work experience. Moreover, the prevalence of anxiety was $69 \%$ higher for seafarers in the 21 to 25 years old age group compared to seafarers in the $>25$ years old age group (aPR 1.69; 95\% Cl 1.05-2.72). Furthermore, non-Catholic seafarers had both a higher prevalence of anxiety (aPR 1.86; 95\% Cl 1.15-3.00) and depression (aPR 1.62; 95\% Cl 1.06-2.48) compared to Catholic seafarers (Table 2).

\section{DISCUSSION}

Globally, there is increasing recognition of the effect of mental health conditions on working populations. Seafarers are among the occupational workers at most risk for adverse mental health outcomes [36]. Generally, the seafarers' mental health and health-related quality of life are poor [37]. In addition, mental health issues such as depression and anxiety are recognised as health problems [38]. Currently, there is limited research on occupational exposures and mental health among international seafarers [39]. Different factors, including months or years away from home, and loneliness, may trigger anxiety and depression, and for some seafarers, even suicide [19].

Our study showed that approximately $37 \%$ and $30 \%$ of the cargo seafarers had mild, moderate, or severe depression and anxiety. Using the same screening tools to assess depression and anxiety, one study reported about $25 \%$ and $17 \%$ had scores suggesting depression and anxiety, respectively, among international seafarers [39]. In another study on Chinese seafarers, almost half had mild to severe depression [40]. Our research also provided further understanding of the psychosocial health risks among international seafarers, including Filipinos, who are among the world's top seafarers. Nevertheless, with the different reported prevalence of anxiety and depression 


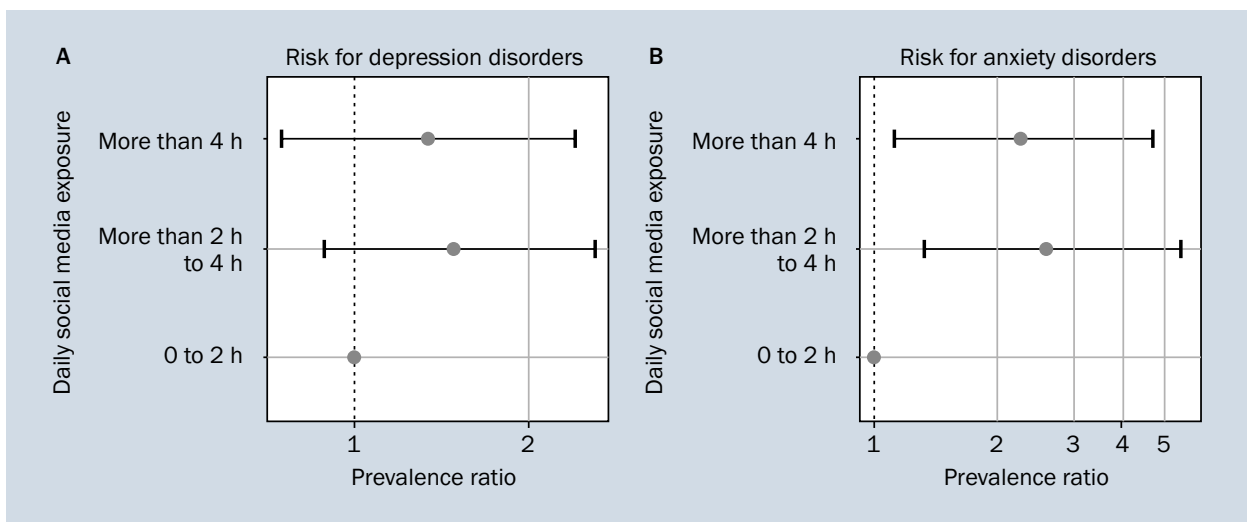

Figure 1. Adjusted prevalence ratio for the effect of daily social media use on depression (A) and anxiety (B) disorders. All models were adjusted for age (young adult [21-25 years old], adult [ $>25$ years old]); in a relationship status (yes, no); education (at least a college graduate, college level or less); Nationality (Filipino, non-Filipino); religion (Catholic, non-Catholic); work experience (>10 years, 10 years or less); on current contract (> 6 months, 6 months or less); and officer of the ship (yes, no). Error bars indicate 95\% confidence interval

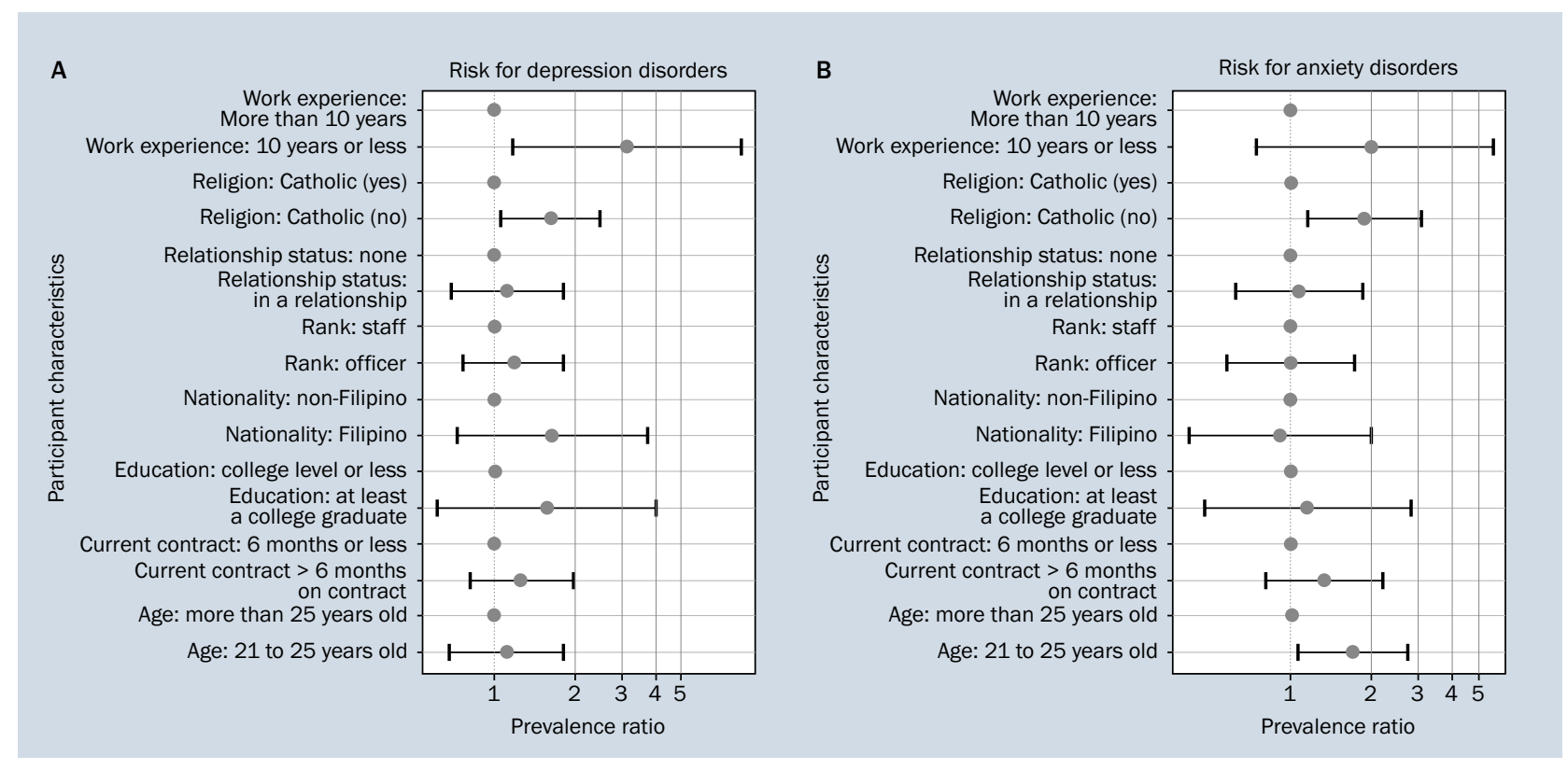

Figure 2. Adjusted prevalence ratio for the effect of occupational experience and socio-economic factors on depression (A) and anxiety (B) disorders. All models were adjusted for age (young adult [21-25 years old], adult [ 25 years old]; in a relationship status (yes, no); education (at least a college graduate, college level or less); Nationality (Filipino, non-Filipino); religion (Catholic, non-Catholic); work experience (> 10 years, 10 years or less); on current contract (> 6 months, 6 months or less); and officer of the ship (yes, no). Error bars indicate $95 \%$ confidence interval

among seafarers, more studies are warranted to validate our research findings.

Understanding social media's effect on well-being has become necessary due to a simultaneous increase in mental health problems, including depression and anxiety [41]. Our study's result that suggests a positive association between daily social media use and depression and anxiety is in agreement with several previous studies that reported the associations between the increased use of social media and heightened levels of depression and anxiety [42-46].
However, other studies have also reported mixed or no relationship [47].

We also observed evidence that anxiety is significantly associated with $>2$ to 4 hours and more than 4 hours of daily exposure to social media than those who usually spent 0 to 2 hours on social media. Similarly, a study of adults published that people who were addicted to social media reported more anxiety [48]. One explanation could be that social media sites may be a source of stress that could contribute to elevated anxiety disorders and related 
Table 2. Adjusted prevalence ratio (PR) with $95 \%$ confidence interval $(95 \% \mathrm{Cl})$ for the effects of daily social media use, occupational experience, and socio-economic factors on depression and anxiety disorders

\begin{tabular}{|c|c|c|}
\hline Characteristics & PR for depression (95\% Cl) & PR for anxiety $(95 \% \mathrm{CI})$ \\
\hline \multicolumn{3}{|l|}{ Daily social media use: } \\
\hline 0 to 2 hours & 1.0 & 1.0 \\
\hline$>2$ to 4 hours & $1.49(0.86,2.60)$ & $2.68(1.30,5.50)$ \\
\hline$>4$ hours & $1.34(0.75,2.40)$ & $2.27(1.12,4.62)$ \\
\hline \multicolumn{3}{|l|}{ Age: } \\
\hline$>25$ years old & 1.0 & 1.0 \\
\hline 21 to 25 years old & $1.11(0.68,1.80)$ & $1.69(1.05,2.72)$ \\
\hline \multicolumn{3}{|l|}{ Relationship status: } \\
\hline No relationship & 1.0 & 1.0 \\
\hline In a relationship & $1.11(0.69,1.79)$ & $1.07(0.62,1.85)$ \\
\hline \multicolumn{3}{|l|}{ Education: } \\
\hline College level or less & 1.0 & 1.0 \\
\hline At least a college graduate & $1.57(0.61,4.00)$ & $1.15(0.48,2.78)$ \\
\hline \multicolumn{3}{|l|}{ Religion: } \\
\hline Catholic & 1.0 & 1.0 \\
\hline Non-Catholic & $1.62(1.06,2.48)$ & $1.86(1.15,3.00)$ \\
\hline \multicolumn{3}{|l|}{ Nationality: } \\
\hline Non-Filipino & 1.0 & 1.0 \\
\hline Filipino & $1.64(0.72,3.74)$ & $0.92(0.42,2.01)$ \\
\hline \multicolumn{3}{|l|}{ Work experience: } \\
\hline$>10$ years & 1.0 & 1.0 \\
\hline$\leq 10$ years & $3.11(1.16,8.36)$ & $2.02(0.73,5.61)$ \\
\hline \multicolumn{3}{|l|}{ Months in current contract: } \\
\hline 6 months or less & 1.0 & 1.0 \\
\hline$>6$ months & $1.26(0.81,1.96)$ & $1.33(0.80,2.20)$ \\
\hline \multicolumn{3}{|l|}{ Employment status: } \\
\hline Staff & 1.0 & 1.0 \\
\hline Officer & $1.18(0.76,1.83)$ & $1.00(0.58,1.73)$ \\
\hline
\end{tabular}

impairments [49]. Another hypothesis is that exposure to social media triggers unhelpful social comparisons, such as believing that others are happier and have better lives [50]. One research among adults in the United States reported participants spent an average of 6.63 hours on social media, and a higher daily social media use was significantly associated with more significant dispositional anxiety disorders [51]. The previous studies' results are consistent with our findings of a higher risk of anxiety from increased social media use.

Our study also suggests that increased daily social media use is associated with the risk of depression. Our findings are supported by previous studies that show evidence of a greater risk of depression for spending more time than spending less time on social media $[52,53]$. One study of 1730 adults who used the same tool to assess depression reported participants who highly used social media in terms of time spent, frequency, multiple platforms, and intensity increased the odds of having elevated depression by 2 times
[52]. In comparison, another study of young adults had found that social media use was significantly associated with increased depression by 2 times [53]. These studies confirmed the results of our research, which also observed similar positive effect estimates. Several studies have related social media use with declines in subjective mood, sense of well-being, life satisfaction, and an increase in depression $[50,54,55]$. One probable explanation may be that constant exposure to idealized representations of people on social media provokes thoughts of envy and the distorted belief that others lead happier lives, and these envious feelings may lead to depression over time [56, 57]. Moreover, the significant increase in the amount of time one spends on social media has led to recognising a specific psychiatric condition called "internet addiction" closely associated with depression [58]. To further understand the effect of social media on seafarers' overall mental well-being, future studies are needed to focus on studies assessing the links of psychological well-being, social media usage, and 
various neutral outcomes such as general job satisfaction, resilience, and subjective happiness among seafarers.

Our study suggested that working for 10 years or less as a cargo seafarer will likely increase the risks of developing depression or anxiety, which may be attributed to not being accustomed to the work routines, or being away from their family. However, continuous long years of separation, time pressure, and long working days with few opportunities for communication and the feelings of social isolation were reported in previous studies to contribute to the detrimental impact and dilapidation on seafarers' mental health, including anxiety and depression $[19,59-63]$. Nonetheless, more studies are needed to support the findings of our research.

In addition, our observed association between being a Catholic and a lower risk of anxiety and depression were in agreement with past studies. In a prospective study, Catholic adults with high personal importance of religion or spirituality had about one-fourth the risk of having depression or anxiety episodes than adults who did not value spirituality that much [64]. The protective effect of religion or spirituality against the risk for depression or anxiety among high-risk groups was found to exist primarily against recurrence rather than onset [65]. Spiritual practice may be associated with physiological and morphological changes in the brain, including increases in serotonin, leading to decreased risk for depression or anxiety [66].

To our knowledge, this is the first study conducted with Filipino seafarers that assessed the association between their daily social media usage and their risk for depression and anxiety disorders. Furthermore, an electronic survey questionnaire tool ensures efficient and timely data collection and limits the number of missing data from the respondents. In addition, the use of generalised linear models with Poisson distribution and log link function to analyse cross-sectional data with common health outcomes reduces overestimation of effect estimates, provides narrower confidence interval(s), and are relatively robust to omitted (residual) factors compared to logistic regression models [30, 33].

\section{LIMITATIONS OF THE STUDY}

One of our study's limitations is the use of a cross-sectional study design; contrasts were mainly between participants from a one-time point, and a temporal association between the exposure variables and anxiety and depression cannot be measured. Additionally, our study did not assess the bidirectional relations between mental health and social media use, which should not be dismissed. The interactions of religion and age with social media use should be addressed in future studies. The younger generation has been identified as less religious, and their use of social media continues to rise. Consequently, confounding factor bias would be more than in a longitudinal study design, which can account for the contrasts for both between and within-subjects. Moreover, unmeasured or residual confounding factor bias should not be omitted. Because the study population consists of all male merchant seafarers who are mostly Filipino, our study's findings may not be generalisable to other occupational groups, women, teenagers, children, or other ethnic or racial groups. Daily social media use on the risk of depression and anxiety in these populations should be explored in future research.

\section{CONCLUSIONS}

This study documents that daily social media exposure for $>2$ hours may increase the risk of anxiety and depression among cargo seafarers. In addition, susceptibility to increased risk of depression and anxiety is more likely to occur among cargo seafarers with ten years or less experience. However, being a Catholic cargo seafarer may suggest being protected from the risk of anxiety and depression. This study also showed that different levels of anxiety and depression are expected among cargo seafarers. Lastly, our results provided information that can be useful for support groups for seafarers. Considering the amount of time spent by most seafarers on social media, this can also serve as a potential avenue to disseminate health information and promote mental well-being.

\section{ACKNOWLEDGEMENTS}

We would like to thank the Fr. Jordy Bago and Port Chaplain Jörg Pfautsch of Antwerp Seafarers' Center (ASC) and the Stella Maris Antwerp for generously providing the space and avenue to conduct the data collection for this study. We also thank ISWAN's SeafarerHelp, Lubag-Sison, and Cruz family, and all the staff and student volunteers at the Centre for their active role in the participant recruitment. For Dr. Elaine Lebon-McGregor and Dr. Michaella Vanore of Maastricht University for their valuable insight on labour migration and its psychosocial effects to seafarers and their families. Lastly, we would like to thank all seafarers and their families who shared their time to participate in this survey.

\section{REFERENCES}

1. Junianto $E$, Rachman R. Implementation of text mining model to emotions detection on social media comments using particle swarm optimization and naive bayes classifier. 2019 7th International Conference on Cyber and IT Service Management (CITSM). 2019, doi: 10.1109/citsm47753.2019.8965382.

2. Davis S. Objectification, sexualization, and misrepresentation: social media and the college experience. Social Media + Society. 2018; 4(3): 205630511878672 , doi: 10.1177/2056305118786727.

3. Best P, Manktelow R, Taylor B. Online communication, social media and adolescent wellbeing: A systematic narrative review. Children Youth Services Rev. 2014; 41: 27-36, doi: 10.1016/j. childyouth.2014.03.001. 
4. Seabrook EM, Kern ML, Rickard NS. Social networking sites, depression, and anxiety: a systematic review. JMIR Ment Health. 2016; 3(4): e50, doi: 10.2196/mental.5842, indexed in Pubmed: 27881357.

5. Sepanlou SG, Parsaeian M, Krohn KJ, et al. Disability-Adjusted Life-Years (DALYs) for 315 Diseases and Injuries and Healthy Life Expectancy (HALE) in Iran and its Neighboring Countries, 1990-2015: Findings from Global Burden of Disease Study 2015. Arch Iran Med. 2017; 20(7): 403-418, indexed in Pubmed: 28745902.

6. Stansfeld S. Chapter 2: Common mental disorders. Mental health and wellbeing in England: adult psychiatric morbidity survey. 20142016.

7. Cramer S. Statusofmind: Social Media and Young People's Mental Health and Wellbeing. in APHA's 2018 Annual Meeting \& Expo (Nov. 10-Nov. 14). 2018. American Public Health Association.

8. Thibaut F. Anxiety disorders: a review of current literature. Dialogues Clin Neurosci. 2017; 19(2): 87-88, indexed in Pubmed: 28867933.

9. Gore F, Bloem P, Patton G, et al. Global burden of disease in young people aged 10-24 years: a systematic analysis. Lancet. 2011; 377(9783): 2093-2102, doi: 10.1016/s0140-6736(11)60512-6.

10. Hetrick SE, Cox GR, Witt KG, et al. Cognitive behavioural therapy (CBT), third-wave CBT and interpersonal therapy (IPT) based interventions for preventing depression in children and adolescents. Cochrane Database Syst Rev. 2016(8): CD003380, doi: 10.1002/14651858.CD003380.pub4, indexed in Pubmed: 27501438.

11. Morgan C, Webb RT, Carr MJ, et al. Incidence, clinical management, and mortality risk following self harm among children and adolescents: cohort study in primary care. BMJ. 2017; 359: j4351, doi: 10.1136/bmj.j4351, indexed in Pubmed: 29046278.

12. Greenberg PE, Fournier AA, Sisitsky T, et al. The economic burden of adults with major depressive disorder in the United States (2005 and 2010). J Clin Psychiatry. 2015; 76(2): 155-162, doi: 10.4088/ JCP.14m09298, indexed in Pubmed: 25742202.

13. Hoffman DL, Dukes EM, Wittchen HU. Human and economic burden of generalized anxiety disorder. Depress Anxiety. 2008; 25(1): 72-90, doi: 10.1002/da.20257, indexed in Pubmed: 17146763.

14. Birnbaum HG, Kessler RC, Kelley D, et al. Employer burden of mild, moderate, and severe major depressive disorder: mental health services utilization and costs, and work performance. Depress Anxiety. 2010; 27(1): 78-89, doi: 10.1002/da.20580, indexed in Pubmed: 19569060.

15. Saveanu RV, Nemeroff CB. Etiology of depression: genetic and environmental factors. Psychiatr Clin North Am. 2012; 35(1): 51-71, doi: 10.1016/j.psc.2011.12.001, indexed in Pubmed: 22370490.

16. Ramirez SZ. Fears and Anxiety Disorders, in In Children's needs III: Development, prevention and intervention, G. Bear and K. Minke, Ed. National Association of School Psychologists, Washington, DC 2006: 267-279.

17. Oldenburg M, Herzog J, Harth V. Seafarer deaths at sea: a German mortality study. Occup Med (Lond). 2016; 66(2): 135-137, doi: 10.1093/occmed/kqv153, indexed in Pubmed: 26409049.

18. Mellbye A, Carter T. Seafarers' depression and suicide. Int Marit Health. 2017; 68(2): 108-114, doi: 10.5603/IMH.2017.0020, indexed in Pubmed: 28660614.

19. Iversen RTB. The mental health of seafarers. Int Marit Health. 2012; 63(2): 78-89, indexed in Pubmed: 22972547.

20. Abaya AR, Roldan S, Ongchangco JC, et al. Repatriation rates in Filipino seafarers: a five-year study of 6,759 cases. Int Marit Health. 2015; 66(4): 189-195, doi: 10.5603/IMH.2015.0038, indexed in Pubmed: 26726888.

21. Roberts SE, Jaremin B, Chalasani $P$, et al. Suicides among seafarers in UK merchant shipping, 1919-2005. Occup Med (Lond). 2010;
60(1): 54-61, doi: 10.1093/occmed/kqp133, indexed in Pubmed: 19805397.

22. Baharudin B, Lee L, Khan K. A review of machine learning algorithms for text-documents classification. J Advances Information Techn. 2010; 1(1), doi: 10.4304/jait.1.1.4-20.

23. Maras D, Flament MF, Murray M, et al. Screen time is associated with depression and anxiety in Canadian youth. Prev Med. 2015; 73: 133-138, doi: 10.1016/j.ypmed.2015.01.029, indexed in Pubmed: 25657166.

24. LiX, Buxton OM, Lee S, et al. Sleep mediates the association between adolescent screen time and depressive symptoms. Sleep Med. 2019; 57: 51-60, doi: 10.1016/j.sleep.2019.01.029, indexed in Pubmed: 30897456.

25. Bottino SM, Bottino CMC, Regina CG, et al. Cyberbullying and adolescent mental health: systematic review. Cad Saude Publica. 2015; 31(3): 463-475, doi: 10.1590/0102-311×00036114, indexed in Pubmed: 25859714

26. Koenig H, McCullough M, Larson D. Handbook of Religion and Health. Oxford University Press, New York. 2001, doi: 10.1093/ acprof:oso/9780195118667.001.0001.

27. Spitzer RL, Kroenke K, Williams JBW, et al. A brief measure for assessing generalized anxiety disorder: the GAD-7. Arch Intern Med. 2006; 166(10): 1092-1097, doi: 10.1001/archinte.166.10.1092, indexed in Pubmed: 16717171

28. Kroenke K, Spitzer RL, Williams JB. The PHQ-9: validity of a brief depression severity measure. J Gen Intern Med. 2001; 16(9): 606-613, doi: 10.1046/j.1525-1497.2001.016009606.x, indexed in Pubmed: 11556941.

29. Kroenke K, Wu J, Yu Z, et al. Patient health questionnaire anxiety and depression scale: initial validation in three clinical trials. Psychosom Med. 2016; 78(6): 716-727, doi: 10.1097/ PSY.0000000000000322, indexed in Pubmed: 27187854.

30. McNutt LA, Wu C, Xue X, et al. Estimating the relative risk in cohort studies and clinical trials of common outcomes. Am J Epidemiol. 2003; 157(10): 940-943, doi: 10.1093/aje/kwg074, indexed in Pubmed: 12746247.

31. Spiegelman D, Hertzmark E. Easy SAS calculations for risk or prevalence ratios and differences. Am J Epidemiol. 2005; 162(3): 199-200, doi: 10.1093/aje/kwi188, indexed in Pubmed: 15987728.

32. Tamhane AR, Westfall AO, Burkholder GA, et al. Prevalence odds ratio versus prevalence ratio: choice comes with consequences. Stat Med. 2016; 35(30): 5730-5735, doi: 10.1002/sim.7059, indexed in Pubmed: 27460748.

33. Zou G. A modified poisson regression approach to prospective studies with binary data. Am J Epidemiol. 2004; 159(7): 702-706, doi: 10.1093/aje/kwh090, indexed in Pubmed: 15033648.

34. Taylor RR, Jason LA, Jahn SC. Chronic fatigue and sociodemographic characteristics as predictors of psychiatric disorders in a community-based sample. Psychosom Med. 2003; 65(5): 896-901, doi: 10.1097/01.psy.0000088580.28749.7f, indexed in Pubmed: 14508038.

35. Solomou I, Constantinidou F. Prevalence and predictors of anxiety and depression symptoms during the COVID-19 pandemic and compliance with precautionary measures: age and sex matter. Int J Environ Res Public Health. 2020; 17(14), doi: 10.3390/ ijerph17144924, indexed in Pubmed: 32650522.

36. Jeżewska M, Leszczyńska I, Jaremin B. Work-related stress in seamen. Int Marit Health. 2006; 57(1-4): 66-75, indexed in Pubmed: 17312695.

37. Hjarnoe L, Leppin A. Health promotion in the Danish maritime setting: challenges and possibilities for changing lifestyle behavior and 
health among seafarers. BMC Public Health. 2013; 13: 1165, doi: 10.1186/1471-2458-13-1165, indexed in Pubmed: 24330425.

38. Carter T, Schreiner A. Textbook of maritime medicine. Norwegian Centre for Maritime Medicine, Bergen 2013.

39. Lefkowitz RY, Slade MD. Seafarer Mental Health Study. ITF Seafarers Trust \& Yale University: ITF House, 49-60 Borough Road, London SE1 1DR, United Kingdom 2019.

40. Xiao J, Huang B, Shen H, et al. Association between social support and health-related quality of life among Chinese seafarers: A cross-sectional study. PLoS One. 2017; 12(11): e0187275, doi: 10.1371/ journal.pone.0187275, indexed in Pubmed: 29176809.

41. Kim HHS. The impact of online social networking on adolescent psychological well-being (WB): a population-level analysis of Korean school-aged children. Int J Adolescence Youth. 2017; 22(3): 364-376, doi: 10.1080/02673843.2016.1197135.

42. Hunt M, Marx R, Lipson C, et al. No More FOMO: Limiting Social Media Decreases Loneliness and Depression. J Social Clin Psychology. 2018; 37(10): 751-768, doi: 10.1521/ jscp.2018.37.10.751.

43. Banjanin N, Banjanin N, Dimitrijevic I, et al. Relationship between internet use and depression: Focus on physiological mood oscillations, social networking and online addictive behavior. Computers Human Behavior. 2015; 43: 308-312, doi: 10.1016/j. chb.2014.11.013.

44. Barry CT, Sidoti CL, Briggs SM, et al. Adolescent social media use and mental health from adolescent and parent perspectives. J Adolesc. 2017; 61: 1-11, doi: 10.1016/j.adolescence.2017.08.005, indexed in Pubmed: 28886571.

45. Pantic I, Damjanovic A, Todorovic J, et al. Association between online social networking and depression in high school students: behavioral physiology viewpoint. Psychiatr Danub. 2012; 24(1): 90-93, indexed in Pubmed: 22447092.

46. Woods HC, Scott H. \#Sleepyteens: Social media use in adolescence is associated with poor sleep quality, anxiety, depression and low self-esteem. J Adolesc. 2016; 51: 41-49, doi: 10.1016/j.adolescence.2016.05.008, indexed in Pubmed: 27294324.

47. Jelenchick LA, Eickhoff JC, Moreno MA. "Facebook depression?" social networking site use and depression in older adolescents. J Adolesc Health. 2013; 52(1): 128-130, doi: 10.1016/j.jadohealth.2012.05.008, indexed in Pubmed: 23260846.

48. Schou Andreassen C, Billieux J, Griffiths MD, et al. The relationship between addictive use of social media and video games and symptoms of psychiatric disorders: A large-scale cross-sectional study. Psychol Addict Behav. 2016; 30(2): 252-262, doi: 10.1037/ adb0000160, indexed in Pubmed: 26999354.

49. Mauri M, Cipresso P, Balgera A, et al. Why is Facebook so successful? Psychophysiological measures describe a core flow state while using Facebook. Cyberpsychol Behav Soc Netw. 2011; 14(12): 723-731, doi: 10.1089/cyber.2010.0377, indexed in Pubmed: 21879884.

50. Chou HTG, Edge N. "They are happier and having better lives than I am": the impact of using Facebook on perceptions of others' lives. Cyberpsychol Behav Soc Netw. 2012; 15(2): 117-121, doi: 10.1089/cyber.2011.0324, indexed in Pubmed: 22165917.

51. Vannucci A, Flannery KM, Ohannessian CM. Social media use and anxiety in emerging adults. J Affect Disord. 2017; 207:
163-166, doi: 10.1016/j.jad.2016.08.040, indexed in Pubmed: 27723539.

52. Shensa A, Sidani JE, Dew MA, et al. Social media use and depression and anxiety symptoms: a cluster analysis. Am J Health Behav. 2018; 42(2): 116-128, doi: 10.5993/AJHB.42.2.11, indexed in Pubmed: 29458520.

53. Lin LYi, Sidani JE, Shensa A, et al. Association between social media use and depression among US young adults. Depress Anxiety. 2016; 33(4): 323-331, doi: 10.1002/da.22466, indexed in Pubmed: 26783723.

54. Kross E, Verduyn P, Demiralp E, et al. Facebook use predicts declines in subjective well-being in young adults. PLoS One. 2013; 8(8): e69841, doi: 10.1371/journal.pone.0069841, indexed in Pubmed: 23967061.

55. Sagioglou C, Greitemeyer T. Facebook's emotional consequences: Why Facebook causes a decrease in mood and why people still use it. Computers Human Behavior. 2014; 35: 359-363, doi: 10.1016/j. chb.2014.03.003.

56. Smith RH, Kim SH. Comprehending envy. Psychological Bulletin. 2007; 133(1): 46.

57. Krasnova $\mathrm{H}$ et al. Envy on Facebook: a hidden threat to users' life satisfaction? in In: Proceedings of the 11th International Conference on Wirtschaftsinformatik (WI2013). 2013. Universität Leipzig, Germany: BORIS Standard License.

58. Block JJ. Issues for DSM-V: internet addiction. Am J Psychiatry. 2008; 165(3): 306-307, doi: 10.1176/appi.ajp.2007.07101556, indexed in Pubmed: 18316427.

59. Roberts SE, Marlow PB. Traumatic work related mortality among seafarers employed in British merchant shipping, 1976-2002. Occup Environ Med. 2005; 62(3): 172-180, doi: 10.1136/ oem.2003.012377, indexed in Pubmed: 15723882.

60. Oldenburg $\mathrm{M}$, Jensen $\mathrm{HJ}$, Wegner R. Burnout syndrome in seafarers in the merchant marine service. Int Arch Occup Environ Health. 2013; 86(4): 407-416, doi: 10.1007/s00420-012-0771-7, indexed in Pubmed: 22526089.

61. Oldenburg M, Jensen $\mathrm{HJ}$, Latza U, et al. Seafaring stressors aboard merchant and passenger ships. Int J Public Health. 2009; 54(2): 96-105, doi: 10.1007/s00038-009-7067-z, indexed in Pubmed: 19288290.

62. Rohde N, D'Ambrosio C, Tang K, et al. Estimating the mental health effects of social isolation. Applied Res Quality of Life. 2015; 11(3): 853-869, doi: 10.1007/s11482-015-9401-3.

63. Shattell M, Apostolopoulos Y, Sönmez S, et al. Occupational stressors and the mental health of truckers. Issues Ment Health Nurs. 2010; 31(9): 561-568, doi: 10.3109/01612840.2010.488783, indexed in Pubmed: 20701418.

64. Miller L, Wickramaratne P, Gameroff MJ, et al. Religiosity and major depression in adults at high risk: a ten-year prospective study. Am J Psychiatry. 2012; 169(1): 89-94, doi: 10.1176/appi. ajp.2011.10121823, indexed in Pubmed: 21865527.

65. Koenig HG, George LK, Peterson BL. Religiosity and remission of depression in medically ill older patients. Am J Psychiatry. 1998; 155(4): 536-542, doi: 10.1176/ajp.155.4.536, indexed in Pubmed: 9546001.

66. Newberg AB. Transformation of brain structure and spiritual and spiritual experience, in The Oxford handbook of psychology and spirituality. Oxford University Press, New York 2012: 489-499. 